\title{
Metaphoric Perception of Coach Candidates towards Swimming Discipline: A Qualitative, Cognitive Research
}

\author{
Cemal Gündoğdu ${ }^{1}$, Yalın Aygün ${ }^{1}$ \\ ${ }^{1}$ Faculty of Sport Sciences, Inonu University, Malatya, Turkey \\ Correspondence: Yalın Aygün, Faculty of Sport Sciences, Inonu University, 44280, Malatya, Turkey.
}

Received: December 2, 2017

Accepted: January 9, 2018

Online Published: January 20, 2018

doi:10.11114/jets.v6i2.2835

URL: https://doi.org/10.11114/jets.v6i2.2835

\begin{abstract}
This research evinces the value of the multidimensional perceptions of the metaphors towards swimming discipline and its relevant certain contexts according to swimming coach candidates. In this article, we used qualitative research paradigm away from positivist approaches to describe and interpret stories and personal experiences of the participants. Fifty-five undergraduate senior students who studied in the department of coaching education in a large South-eastern university were secured homogenously (aged between 21 and 29). Using a semi-structured interview form, data were generated based on six predetermined contexts: swimming, swimming coach, freestyle, backstroke, breaststroke, and butterfly. Each context focused participants' metaphor generation processes. As data generation continued, we also intended to be participant-observer to gain epistemological privilege by participating in and experiencing what is going on. Within the predetermined contexts, thematic analysis conducted through a software package of NVivo 11 Plus emerged seventeen conditions (sub-themes). In the portrait gallery of metaphoric perceptions of coach candidates towards swimming discipline, we found variety in the mental images of each context.
\end{abstract}

Keywords: coaching, metaphor generation, undergraduate students, swimming training

\section{Introduction}

Researchers with a social-cognitive orientation focus on how knowledge of the specific situation is determined by a complex interaction between the environment and one's personal makeup (Weinberg \& Daniel, 2015). In this context, Albert Bandura's (1986) social-cognitive theory recognizes symbolizing as a fundamental human capability. Moreover, the theory regards that symbols serve as the vehicle of thought; by symbolizing their experience, people give structure, meaning, and continuity to their lives.

Using metaphor, researchers might examine how perception through its underlying cognitive processes occurs in the brain, however. A metaphor (from Greek metafora-to transfer) is defined as an ordinary expression, often found in imaginative figure of speech, that describes an object or action by referring to something that is considered to have similar characteristics to that object or action (Cambridge english dictionary, 2017). Metaphor was first developed in 1980 by Lakoff and Johnson's work of "Metaphors we live by". Their idea in this work known as the starting point of the renewal interest in metaphors in the field of cognitive linguistics view (Lakoff \& Johnsen, 1980). Metaphors are effective theoretical tools for explaining ideas, collecting information, and enlightening understanding (Combs \& Freedman, 1990). In other words, a metaphor usually stands for something else and it uses words, objects, mental images, stories, etc. as holistic and meaningful units (Combs \& Freedman, 1990). For example, it is raining cats and dogs out! Thus, a metaphor provides a picture of one's understanding of complex issues or new situations by mapping an experience in the terminology of another experience (Medin \& Ortony, 1989).

The scope of the previous research on metaphor in sport is not scant. Existing research into sport metaphor has focus on qualitative measures of performance related emotional states (Hanin \& Stambulova, 2002; Hanin, 2003; Ruiz \& Hanin, 2004), therapeutic activity (Clarke, 2009; Spander, Roy, \& Mckeown, 2014), career problems of athletes (Triggs, Lafferty, Brown, \& Tolley, 2011), sport, aesthetic experience and art relations (Elcombe, 2012) or conceptualization of sport (Dervent, 2016). Research addressing the overview of the swimming metaphors as a cognitive-oriented framework for qualitative, quantitative or mixed methods approach typically has not been conducted. This is the unique contribution of our research. Present article, on the other side, has a disadvantage arising from deficiency of assistive quantitative methods to make some form of wider claim about generalizability on the basis of our research and analysis. 
Future research, however, can combine qualitative and quantitative methods to capture synergistic approach in an attempt to gain greater insight into the studied phenomenon.

Swimming, in sport, can be defined as a vehicle to certain activities and interrelated skills that technically transferred into practice in water. From the sport swimming perspective, professionals might use metaphors to assist the processes of gathering evidence of knowledge or facilitating new facts of thought, feelings, perceptions, insider views, etc. pertaining to this discipline. Perceptions of coach candidates towards swimming discipline might be meaningful components of the social world. To address the intellectual and theoretical contributions of this work, we formulated a research puzzle (Mason, 2002): How we can explain the metaphors towards swimming and its related certain contexts given by coach candidates?

The goals of the article are:

1. To demonstrate the use of a qualitative research design that reveals opportunity to explain what happens "inside" investigated social phenomenon.

2. To evaluate the open-ended questions, as a qualitative research tool for generating data in a shared representative sample of a semi-structured interview form.

3. To infer research conclusions from the qualitative research strand.

The primary purpose of this article was to report and discuss the multidimensional perceptions of the metaphors of swimming discipline and its relevant certain contexts according to swimming coach candidates.

\section{Method}

\subsection{Research Design}

This phase briefly refers to implementation of the qualitative research strand through selection of research group, data generation, and procedures of the analysis stage.

The focus of our research was to better understand the perceptions of coach candidates towards swimming, and its related certain contexts in relation to the use of metaphors. Exploring these complex relationships helped us to provide greater insight into the development of research thinking. The following two overarching research questions further clarified the direction of the article: What are the metaphoric perceptions of coach candidates towards swimming, swimming coach, freestyle, backstroke, breaststroke and butterfly? How are metaphors given by coach candidates explained to see the bigger picture of the research thinking?

In this article, we used qualitative research paradigm away from positivist approaches to describe and interpret stories and personal experiences of the participants (Blaikie, 2009; Denzin \& Lincoln, 2005; Hollway \& Jefferson, 2013). Qualitative, phenomenological approach was also adopted within this paradigm (Creswell, 2007).

\subsection{Participants}

Securing participant for this research involved homogenous recruitment approach (Patton, 2002). This approach required two criteria, saturation and sufficiency (Seidman, 2006). When saturation began to emerge from the data, no further efforts were made to secure participants. Thus, final research group consisted of fifty-five undergraduate senior students from a large South-eastern university (aged between 21 and 29). Being in the class of coaching education in swimming discipline was also considered as a sufficiency criterion for this research. Furthermore, all names of individuals and places were kept confidential, for example: M.1, F.21, M.44, F.25 (M=Male and F=Female).

\subsection{Data Generation: Construction}

Before putting this research into practice, we received an ethics committee approval letter from a state university. Upon completing ethical process, we reviewed the literature and conducted brief interviews with few domain experts in line with the research objectives to create open-ended questions towards our research design. Next, we submitted for expert's opinion about the open-ended questions to put them into operation authentically and validly. We used a semi-structured interview form as data generation tool, and asked the participants fill in the blanks on the form through metaphors. The open-ended questions that guide participants to generate metaphors were consisted of these context: "swimming is like..., because...", "swimming coach is like..., because...", "freestyle is like..., because...", "backstroke is like..., because...", "breaststroke is like..., because...", and "butterfly is like..., because...". In order to ascertain the intelligibleness of the open-ended questions, we hold three pilot interviews prior to actual interview phase. The ultimate interviews ranged in length from 10 to 12 minutes, and each was letter transcribed for use in analysis stage.

As data generation continued, we intended to be participant-observer in a lesson setting of the students to gain epistemological privilege by participating in and experiencing what is going on. Accordingly, we gained access to the swimming pool setting and wrote memos by observing the students. As a consequence, when lecturer selected peer 
learning as special teaching method, we observed that students draw on metaphors during technical education. For example: "like head of a rocket", "like a bird flying", "like a plane landing", etc. At some point, memos indicated that using metaphors among students is common. Focusing on metaphors in technical education of swimming, future research can provide some insight into the study phenomenon, however.

\subsection{Data Analysis}

At the analysing stage of this research, when saturation began to emerge from the data, no further efforts were made to secure participants (Seidman, 2006). In an effort to turn data into evidence which address the research question, thematic analysis was used (Guest, MacQueen, \& Namey, 2012). Verbal evidences were initially coded and organised using NVivo 11 Plus software after having been read line by line to generate initial coding categories. Quantitative content analysis was also used to indicate the frequency of the conditions and codes embedded in the qualitative data. Two authors of the article performed both quantitative and qualitative analysis separately and independently of one another. Following this, the generated data were sorted and then compared and weaved together. Two researchers, sorted the statements into the categories with a high degree of agreement (Cohen's $\mathrm{K}=.91$ ).

\section{Results}

Before data generation, four main contexts of swimming discipline were constituted: swimming, swimming coach, freestyle, backstroke, breaststroke and butterfly. Within each context, 16 conditions (sub-themes) including wide range of codes emerged through student's metaphor generation became apparent.

Table 1. Predetermined contexts and conditions of metaphors towards swimming discipline.

\begin{tabular}{ll}
\hline Context & Condition \\
\hline Swimming & Devotion, Survival, Aesthetics, Happiness, Harmony \\
Swimming Coach & Role Model, Individual Characteristic \\
Freestyle & Building Block, Harmony, Velocity, Freedom \\
Backstroke & Visualization, Discrepancy, Comfort \\
Breaststroke & Visualization, Complexity, Flexibility and Aesthetics, Comfort \\
Butterfly & Visualization, Complexity, Aesthetics, Strength \\
\hline
\end{tabular}

3.1 Swimming Context

As data analysis continued, it appeared that swimming context was related to five prominent conditions (sub-themes): devotion, survival, aesthetics, and harmony.

\subsubsection{Devotion}

Long Journey, Strong wind, rock, matryoshka doll, Suleiman the Magnificent, and Genghis Khan. Swimming is like a long journey. Because it requires long time-consuming labour and time (M.1).

\subsubsection{Survival}

Ship (4), walking unflinchingly, and piece of wood. Swimming is like a ship. Because distance can be achieved by applying certain movements correctly without sinking on the water (M.44).

\subsubsection{Aesthetics}

Fish (7), potty putty (2), bird (2), slide down the slide (2), dolphin (2), dance show, perform ballet, acrobat, plane, and sneak. Swimming is like potty putty. Because when you swim, you get a certain shape by kneading with water like potty putty (M.46).

\subsubsection{Happiness}

Odour, aquarium, bird, water, surfer, freedom, chillness, flying, and sleeping. Swimming is like being in an aquarium. Because it's a field where you can relax and find peace (F.8).

\subsubsection{Harmony}

Clock (2), song, rehabilitation, school, microscopic aquatic creature, jigsaw puzzle, and medicine. Swimming is like a clock. Because a clock works in accord with the hour hand and the minute hand. If one does not work, it does not matter if the other works. Swimming is similar to having arms and legs in harmony (F.28).

\subsection{Swimming Coach Context}

As data analysis continued, it appeared that swimming coach context was related to two prominent conditions 
(sub-themes): role model, and individual characteristic.

\subsubsection{Role Model}

Lighthouse (2), family (2), ship wheel, friend, mother duck, mother fish, moonlight, ship's captain, father, eagle, Poseidon, and shepherd. The swimming coach is like a lighthouse. Because it has a key-role of guiding, light-holding and illuminating from every angle (M.1).

\subsubsection{Individual Characteristics}

Fruit tree (3), encyclopaedia (2), tree (2), dolphin (2), whale (2), fish, Shade of tree, air-conditioner, lifeguard, doctor, trust, life ring, breath, private lesson teacher, grownup fish, Mona Lisa, pine tree, clover, ocean, king in chess, math teacher, water, human brain, gladiator trainer, turtle tamer, octopus, leader, owl, and traffic light. The swimming coach is like a four-leaf clover. Because it is a very rare plant. Each leaf represents a style of swimming, unique (F.21). Swimming coach is like an air-conditioner. Because it provides an environment in any case and under all conditions (M.11).

\subsection{Freestyle Context}

As data analysis continued, it appeared that freestyle context was related to four prominent conditions (sub-themes): building block, harmony, velocity, and freedom.

\subsubsection{Building Block}

Crawling baby, universality, starting point, phone charge, engine, mother, and soil. Freestyle is like a baby's crawling. Because just as a baby learns to crawl before walking, a person learns to freestyle swimming before other swimming styles (M.38).

\subsubsection{Harmony}

Car (3), ride a bicycle (3), wheel (2), running (2), snake, lizard, alligator, engine, weaving rug, wall clock, dancing, singing while running, rowing, and moving while doing a handstand. Freestyle is like singing a song while running. Because breathing, arm pull, foot stroke, etc. must be performed in a well-coordinated manner in freestyle (M.51). Freestyle is like a snake. Because a person floats and slides in the water like a snake in freestyle (F.24).

\subsubsection{Velocity}

Running, plane, bird, ship's crew, and lifeguard. Freestyle is like running. Because it is the fastest way to go on the water (M.40).

\subsubsection{Freedom}

Become free, and leaf. Freestyle is like freedom. Because we can float freely as we like (F.22).

\subsection{Backstroke Context}

As data analysis continued, it appeared that backstroke context was related to three prominent conditions (sub-themes): visualization, discrepancy, and comfort.

\subsubsection{Visualization}

Sleeping (9), rowboat (3), rowing (2), ship (2), canoe (2), bed, mermaid, paper, wood, death, windmill, watermill, rotary wheel, bicycle pedal, slipstream, and sunflower. Backstroke is like a sunflower. Because sunflowers bloom depend on the sun rising. Likewise, swimmers return their faces to sun in the outdoor pool while they return their faces to the overhead light in the indoor pool (F.21).

\subsubsection{Discrepancy}

A different person in a group, person who does not obey the rules, pilates belt, and moving without seeing forward. Backstroke is like a person who does not fit the rules. Because all other swimming styles are performed in the face, only backstroke is performed on the back (F.8).

\subsubsection{Comfort}

Relaxing, soap, sleeping in the hammock, driving, and a person having broken leg. Backstroke is like driving a car. Because this style is so comfortable, it's like driving a car when you're swimming (M.46).

\subsection{Breaststroke Context}

As data analysis continued, it appeared that breaststroke context was related to four prominent conditions (sub-themes): visualization, complexity, flexibility and aesthetics, and comfort. 


\subsubsection{Visualization}

Frog (23), grasshopper (2), window (2), submarine, mole, nippers, scissors, and empathy.

Breaststroke is like a frog. Because the breaststroke and the frog's body shape are compatible (F.25).

\subsubsection{Complexity}

Living conditions (2), removing stones from rice, and Long poplar tree. Breaststroke is like a long poplar tree. Because I can't reach top of it easily (M.37).

\subsubsection{Flexibility and Aesthetics}

Elastic band and belly dance. Breaststroke is like an elastic band. Because if swimmers supple like an elastic band, they swim well (M.32).

\subsubsection{Comfort}

Social activity and calmness. Breaststroke is like calmness. Because you swim without being anxious or uneasy with that style in water (M.40).

\subsection{Butterfly Context}

As data analysis continued, it appeared that butterfly context was related to four prominent conditions (sub-themes): visualization, complexity, aesthetics, and strength.

\subsubsection{Visualization}

Butterfly (8), dolphin (8), eagle (4), fluttering, wave, flying, whale, mermaid, scissors, worm, and Pegasus. Butterfly swimming is like an eagle. Because an eagle opens its wings widely while flying. Swimmers, however, open their arms widely in butterfly swimming (F.26).

\subsubsection{Complexity}

Battle, difficult language learning, a daily struggle for life of a butterfly, climbing up the sand top with barefoot, and being struck in a difficult situation. Butterfly is like learning a difficult language. Because learning and performing of butterfly as a swimming style is tiresome and painful (M.11).

\subsubsection{Aesthetics}

Dance show, work of art, top model car, and Cleopatra. Butterfly is like a dance show. Because we follow the movements of the arms, feet, head synchronously with each other (M.36).

3.6.4 Strength

The most powerful man in the world, Rocky Balboa, short distance race, tiger, and a powerful horse going to battle. When a person swim with butterfly style moves in water like a rampant horse in a battle (F.29).

\section{Discussion}

This research evinces the value of the multidimensional perceptions of the metaphors towards swimming discipline and its relevant certain contexts according to swimming coach candidates capturing qualitative, cognitive research thinking.

Based on the six predetermined contexts, seventeen conditions are evident (see Table 1). These conditions manifest in the metaphor decisions made by the students. Within the devotion condition, students were likely to generate metaphors indicating the difficulties of swimming context. For example, a student described his metaphor generation process saying, swimming is like a long journey. Because it requires long time-consuming labour and time. Apparently, the difficult situations of swimming, such as its different environment, allowed students to generate metaphors in this way. The survival condition described that students generate metaphors towards survival perception of swimming context. One student noted, swimming is like a ship. Because distance can be achieved by applying certain movements correctly without sinking on the water. Swimming might be defined as a way to stop from drowning. This definition might have a relationship with that condition. In aesthetics condition, several students supported the idea of swimming has an aesthetic appearance on the basis of metaphoric perspective. One student indicated, swimming is like potty putty. Because when you swim, you get a certain shape by kneading with water like potty putty. This may have come to the fore because swimming can be involved in aesthetic sport disciplines. Within the happiness condition, students were seemed to generate pleasant metaphors about swimming context. One student expressed, swimming is like being in an aquarium. Because it's a field where you can relax and find peace. Harmony condition appeared to underlie the context of swimming that emerged as part of students' metaphor generation. One student highlighted, swimming is like a clock. Because a clock works in accord with the hour hand and the minute hand. If one does not work, it does not matter if the other works. Thus, swimming is similar to having arms and legs in harmony. This involved synchronized motion 
adaptation with sufficient skills made by a swimmer in water.

However, Babylonian bas-reliefs, Assyrian wall drawings and the most ancient and famous of drawings depicting men swimming with 6,000 years of historical background address the origin of swimming context (Fina, 2017). In essence, these ancient images and symbols might be considered as metaphorical indicators of swimming context.

Students drawn attention to the swimming coaches as role models via metaphors. One student pointed, the swimming coach is like a lighthouse. Because it has a key-role of guiding, light-holding and illuminating from every angle. From the students' metaphorical perspective, a swimming coach is perceived as a role model to his/her athletes. Students also mentioned the swimming coaches' basic qualities and values by addressing their individual characteristics through metaphors. One student pointed, the swimming coach is like a four-leaf clover. Because it is a very rare plant. Each leaf represents a style of swimming, unique. Another student added, swimming coach is like an air-conditioner. Because it provides an environment in any case and under all conditions. It seems that swimming coaches were discussed in a positive way by students.

In general, we weaved the characteristics of a ideal teacher with a ideal coach through a long list of educational philosophers from ancient to postmodern times. From this perspective, we noted, for example, the coach as midwife (Socrates), as an artist in the use of knowledge (Plato), as a role model (Aristotle), as a liberator (Freire), as an educator in accordance with nature (Rousseau), as an existentialist (Frankel), as a mediator (Feuerstein), as child centred (Neill), and as a postmodernist (Arnon \& Reichel 2007; Reichel \& Arnon 2005).

Building block, velocity and freedom conditions solely emerged within the context of freestyle. In building block condition, students made the point that they perceived freestyle as fundamental style in swimming discipline, which assists other three. One student emphasised, freestyle is like a baby's crawling. Because just as a baby learns crawling before walking, a person learns freestyle swimming before other swimming styles. Unlike the other three swimming styles, students generated metaphors towards freestyle in terms of velocity condition. One student stated, freestyle is like running. Because it is the fastest way to go on the water. Few students perceived freestyle as freedom. One student echoed the opinion, freestyle is like freedom. Because we can float freely as we like. The manner of freestyle application and its recommendations might be the reasons of freedom condition occurrence among students. Overall, it seems that students brought freestyle context into forefront through building block, velocity and freedom conditions, away from backstroke, breaststroke and butterfly contexts.

As can be seen in Table 1, visualisation was likely to be a common condition for the contexts of backstroke, breaststroke and butterfly. In fact, all students from these three contexts described their metaphor generation processes in this way. For example, a student described her metaphoric perception regarding butterfly saying, butterfly swimming is like an eagle. Because an eagle opens its wings widely while flying. Swimmers, however, open their arms widely in butterfly swimming. In historical appraisal of swimming discipline, butterfly, as one of three swimming styles, has given its name from an insect species. It is appear that a metaphor has taken on an important role as a tool for determining the name of a universal swimming style. Within the condition of visualisation, another student described breaststroke via a metaphor saying, breaststroke is like a frog. Because the images of breaststroke and the frog are similar. Of 23 students used the term "frog" as a metaphor to address their breaststroke perceptions. Clearly, such focus could have resulted in students' imaginative figure of speech. We could have concluded that "frog", as a metaphor, might be a potential name substituted for breaststroke in swimming discipline.

Students' metaphoric perceptions emerged two comfort conditions for backstroke and breaststroke contexts. The term comfort was acknowledged as a source of emotional and spiritual support in the 18th century (Shove, 2003). After the 18 th century, comfort symbolised capacity to improve physical needs. In an effort to reflect symbols of value, status and worth, the language of comfort uses terms such as convenience, luxury and necessity (Crowley, 2001). Within the comfort condition, students perceived backstroke and breaststroke contexts as comfortable with the positive impact being in the aquatic environment had on their bodies, and their physical capacity to relax in the swimming pool. For example, one student indicated, backstroke is like driving a car. Because this style is so comfortable, it's like driving a car when you're swimming. Another student described his metaphoric perception towards breaststroke saying, breaststroke is like calmness. Because you swim without being anxious or uneasy with that style in water.

Only within the backstroke context, and discrepancy condition was noted by students. For example, one student reported, backstroke is like a person who does not fit the rules. Because all other swimming styles are performed in the face, only backstroke is performed on the back. In the perspective of students, backstroke is separated from other styles via this uniqueness.

In the portrait gallery of metaphoric perceptions of coach candidates, we found variety in the mental images of each context: swimming, swimming coach, freestyle, backstroke, breaststroke, and butterfly. 


\section{Acknowledgements}

An earlier version of this article was presented orally at the International Eurasian Conference on Sport, Education and Society, Antalya, Turkey, on October 13-16, 2016.

\section{Declaration of Conflicting Interests}

The author(s) declared no potential conflicts of interest with respect to the research, authorship, and/or publication of this article.

\section{References}

Ancient origins. (2017). Retrieved October 19, 2017, from http://www.fina.org/content/ancient-origins

Arnon, S., \& Reichel, N. (2007). Who is the ideal teacher? Am I?-Similarity and difference in perception of students of education regarding the qualities of a good teacher and of their own qualities as teachers. Teachersand Teaching: Theory and Practice, 13(5), 441-464. https://doi.org/10.1080/13540600701561653

Bandura, A. (1986). Social foundations of thought and action: A social cognitive theory. Englewood Cliffs, NJ: Prentice Hall.

Blaikie, N. (2009). Designing social research (2nd Editio). Malden, USA: Polity Press.

Cambridge english dictionary: Meanings \& definitions. (2017). Retrieved October 17, 2017, from http://dictionary.cambridge.org/dictionary/english/

Clarke, L. (2009). Football as a metaphor: Learning to cope with life, manage emotional illness and maintain health. Journal of Psychiatric and Mental Health Nursing, 16, 448-492.

Combs, G., \& Freedman, J. (1990). Symbol, story, and ceremony. Using metaphor in individual and family therapy. New York: W.W. Norton \& Company.

Creswell, J. W. (2007). Qualitative inquiry \& research design: choosing among five approaches (2. Bask1). United States of America: Sage Publication Ltd.

Crowley, J. (2001). The invention of comfort: Sensibilities and design in early modern Britain and early America. Baltimore: John Hopkins University Press.

Denzin, N. K., \& Lincoln, Y. (2005). Sage Handbook of qualitative research. Thousand Oaks, CA: Sage.

Dervent, F. (2016). An examination of conceptualization of sport metaphors. Journal of Education and Training Studies, 4(4), 259-268. https://doi.org/10.11114/jets.v4i4.1400

Elcombe, T. L. (2012). Sport, aesthetic experience, and art as the ideal embodied metaphor. Journal of the Philosophy of Sport, 39(2), 201-217. https://doi.org/10.1080/00948705.2012.725901

Guest, G., MacQueen, K., \& Namey, E. (2012). Applied thematic analysis. USA: Sage. https://doi.org/10.4135/9781483384436

Hanin, Y. L. (2003). Performance related emotional states in sport. Forum: Qualitative Social Research, 4(1), 1-31.

Hanin, Y. L., \& Stambulova, N. B. (2002). Metaphoric description of performance states: An application of the IZOF model. The Sport Psychologist, 16(4), 396-415. https://doi.org/10.1123/tsp.16.4.396

Hollway, W., \& Jefferson, T. (2013). Doing qualitative research differently: A psychosocial approach. (K. Metzler, Ed.) (2nd Editio). London: Sage.

Lakoff, G., \& Johnsen, M. (1980). Metaphors we live by. Journal of Philosophy. United States of America: The University of Chicago Press.

Mason, J. (2002). Qualitative researching (2th Editio). Great Britain: Cromwell Press.

Medin, D. L., \& Ortony, A. (1989). Psychological essentialism. Similarity and analogical reasoning. (S. Vasniadou \& A. Ortony, Eds.). New York: Cambridge University Press.

Patton, M. Q. (2002). Qualitative research \& evaluation methods. Qualitative Inquiry (1th editio). United States of America: Sage Publication Ltd.

Reichel, N., \& Arnon, S. (2005). Three portraits of teachers in the view of students of teaching: The ideal teacher, the teacher of teachers and the image of the student him/herself as a teacher. Dapim, 40, 23-58.

Ruiz, M. C., \& Hanin, Y. L. (2004). Metaphoric description and individualized emotion profiling of performance states in top karate athletes. Journal of Applied Sport Psychology, 16(3), 258-273.

https://doi.org/10.1080/10413200490498366 
Seidman, I. (2006). Interviewing as qualitative research: A guide for researchers in education and the social sciences (3th editio). New York: Teacher College Press.

Shove, E. (2003). Comfort, cleanliness and convenience: The social organization of normality. New York: Berg.

Spander, H., Roy, A., \& Mckeown, M. (2014). Using football metaphor to engage men in therapeutşc support. Journal of Social Work Practice, 2(28), 229-245. https://doi.org/10.1080/02650533.2013.853286

Triggs, C., Lafferty, M., Brown, H., \& Tolley, H. (2011). Metaphorical use of song lyrics within sport psychology practice: Targeting the transition within a premier league football youth academy. Journal of Sport Psychology in Action, 2(3), 183-195. https://doi.org/10.1080/21520704.2011.619046

Weinberg, R. S., \& Daniel, G. (2015). Foundations of sport and exercise psychology (6th editio). United States of America: Human Kinetics.

\section{Copyrights}

Copyright for this article is retained by the author(s), with first publication rights granted to the journal.

This is an open-access article distributed under the terms and conditions of the Creative Commons Attribution license which permits unrestricted use, distribution, and reproduction in any medium, provided the original work is properly cited. 